\title{
THE PARTIAL LIFE-HISTORY OF PSEUDOHAZIS EGLANTERINA, WITH REMARKS ON THE LARVAE OF ALLIED GENERA.
}

BY ALPHEUS SPRING PACKARD, PROVIDENCE, R. I.

I am indebted to Prof. C. V. Riley for the opportunity of examining the larvae in alcohol of the first stage of this species, which were collected at Manitou, Col. I have carefully compared these with freshly hatched larvae of $H y$ perchiria io. When first hatched the form of the head and shape of the body are as in $H$. io, but the larva is somewhat larger. The generic differences from $H$. io are confined, not to the number and arrangement of the spiniferous warts, but to the shape of the spines themselves, and this makes it evident that in probably all the genera and species of the hemileucini of Grote, the spines themselves are especially developed at first with reference to the protection of the young larvae, which huddle together in masses so that their bodies are protected from observation. Later in life the spines are smaller in proportion to the body because more scattered, and then it is that the larvae are protected by the poisonous nature of the spines, the body itself being more uncovered and conspicuous. It is just the reverse of what takes place in the arctians and other larvae which become very hairy or bristly late in larval life, and are sparsely provided with hairs when first hatched. It will also be seen that in respect to the spines the present species when first hatched is much more highly specialized than $H$. io, the latter being more simple and generalized a form as regards the spiniferous warts.

Stage 1 .-Length $5 \mathrm{~mm}$. The spiniferous tubercles are arranged, as in $H$. io in eight rows, those of the two rows, one on each side of the median line of the body, and the subdorsal ones being the larger and longer, while those on the side of the body become shorter and smaller as they approach the under side of the body. The spine-bearing warts are larger and swollen compared with those of $H$. io. The dorsal spines on the prothoracic segment* differ from those of H. io in having the trunk spinulated, the spinules being long and each bearing a long, tapering hair; the main spine is pale but ends in two long black forks, each tine of which is $2-3$ as long as the trunk of the spine itself, while the bristle arising from each fork is as long as the latter. The spines of the two lower rows are spinulate on the trunk but are pale throughout, while the larger ones on the back are dark at the end, being pale at the base. The dorsal spines on the abdominal segments

\footnotetext{
* In describing caterpillars it is well, especially in those of bombyces, to distinguish the three first segments behind the head as the thoracic; the ten succeeding ones as the abdominal segments.
} 
differ from those of the thoracic segments in having a somewhat verticillate arrangement of the large five or six terminal spinules, all being pale except the terminal one, which is considerably larger than the others.

The single median spines on the 8th and $9^{\text {th }}$ abdominal segments respectively, occupy the same position as in $H$. io, but are larger in proportion and are not forked as they are in $H$. io; on the contrary they resemble spines, one being larger and darker than the others; the spine on the $9^{\text {th }}$ segment is a little smaller than the one preceding it.

To recapitulate, it will be seen that the spinulate spines of Pseudohazis eglanterina in stage I are more complicated than those of Hyperchiria io of the same stage, so that the body is more concealed from view. The thoracic dorsal spines are forked but not so simply as in $H$. io, while the median single ones on the 8 th and 9 th abdominal segments are not forked but more or less densely spined in irregular whorls, with one of the spines larger than the others.

Fully grown larva.-The following description was drawn up many years ago from between forty or fifty alcoholic specimens from the Gulf of Georgia, Cal., in the Museum of comparative zoology. There was no noticeable variation in the lot. The larva is intermediate in its characters and in size between Hemileuca maia, which it more nearly approaches, and Hyperchiria io. The head is smaller than in either of the two genera mentioned; in the thickness of the body it approaches $H$. io rather than H. maia. The shape of the clypeus is much like that of $H$. maia. The dorsal spines are whorled as in H. maia. The lateral subdivided or whorled setiferous spines are longer than those of the two dorsal rows, but are not so long as in H. maia. The arrangement of the longer spines on the thoracic segments, and on the 8th and

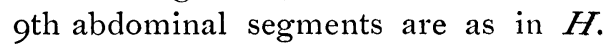
maia, but they are shorter, more bushy and more subdivided. The suranal plate is triangular lunate. The dorsal spines are shorter and sharper than those of $H$. maia, being very sharp and the prick painful even in alcoholic specimens.

The head, body and spines are black; in H. maia the head is reddish, in $H$. io amber. There is no special coloration to mark the larva of $H$. eglanterina, the body in alcoholic specimens being uniformly dark.

Larva of 4 th stage. - The larva in this stage scarcely differs from that in the last stage, the inequality between the length of the dorsal and upper lateral spines is observed in this stage.

Mr. H. Edwards has described (Proc. Cal. acad. sci., 19 April, 1875), the eggs and the mature larva; he states that it feeds on Frangula californica and Rosa. He states that the head is black, and the body entirely dull black. "Each segment is armed with six lateral spines, very finely branched, and two dorsal fascicles of spines, bright chestnut 
color, blackish in the centre. The branchlets of the spines are all bright chestnut in color. Underside as well as the feet and abdominal legs dull black. Length, 2.00 inches."

It is interesting to compare the generic forms. It is usually impossible to draw up comparative descriptions of caterpillars while living, from the obvious fact that one may only have a single species under observation, alive at one time, and for this reason a collection of carefully preserved alcoholic, as well as of blown specimens is all important; and I may add that for the careful study of structural features I much prefer good alcoholic specimens to blown ones, if the caterpillar has been at first killed in very weak alcohol, and, say, a couple of days later transferred to strong alcohol, so that the body does not become too much contracted, and the coloration faded.

I will now add a description of some alcoholic specimens of Hemileuca maia contained in the Museum at Cambridge, drawn up as long ago as 1862 or 1863 . They occurred in New Jersey in July and were compared with Pseudohazis eglanterina.

It is larger, the head larger and dark mahogany in color. There is the same arrangement of spines, but in $H$. maia they are throughout longer than in $P$. eglanterina; they are much stouter, and are paler at the ends. The surface of the body is marbled with pale flat tubercles. The underside of the body is naked, where in P. eglanterina it is somewhat hairy.

At another time I compared mature $H$. maia from Georgia with $H$. io, with the following results. The head in the two genera is of the same size, but in H. maia it narrows towards the vertex. The clypeus of the latter genus is a little larger, and the sides bulge out rather than curve in as in $H$. io, and the surface is more sunken. The body is rather more elongated and slenderer than in $H$. io. There is a median dorsal line, and two subdorsal broad bands, dotted with light oval spots in H. maia. The suranal plate is elongated lunate, approaching a triangular shape. The sides of the anal lip are thickened throughout, more so than in $H$. io.

Note.-The author would take this opportunity to say that he is collecting materials for a monograph of all the Bombyces with especial reference to complete life histories, to be illustrated by colored plates. $\mathrm{He}$ is especially anxious to obtain the eggs of any species of Gastropacha as well as the mature larva, also those of any species of Hemileuca, Pseudohazis and Hyperchiria except those above mentioned, and also desires the eggs and larvae of the species of Euleucophaeus, Coloradia and Quadrina. 

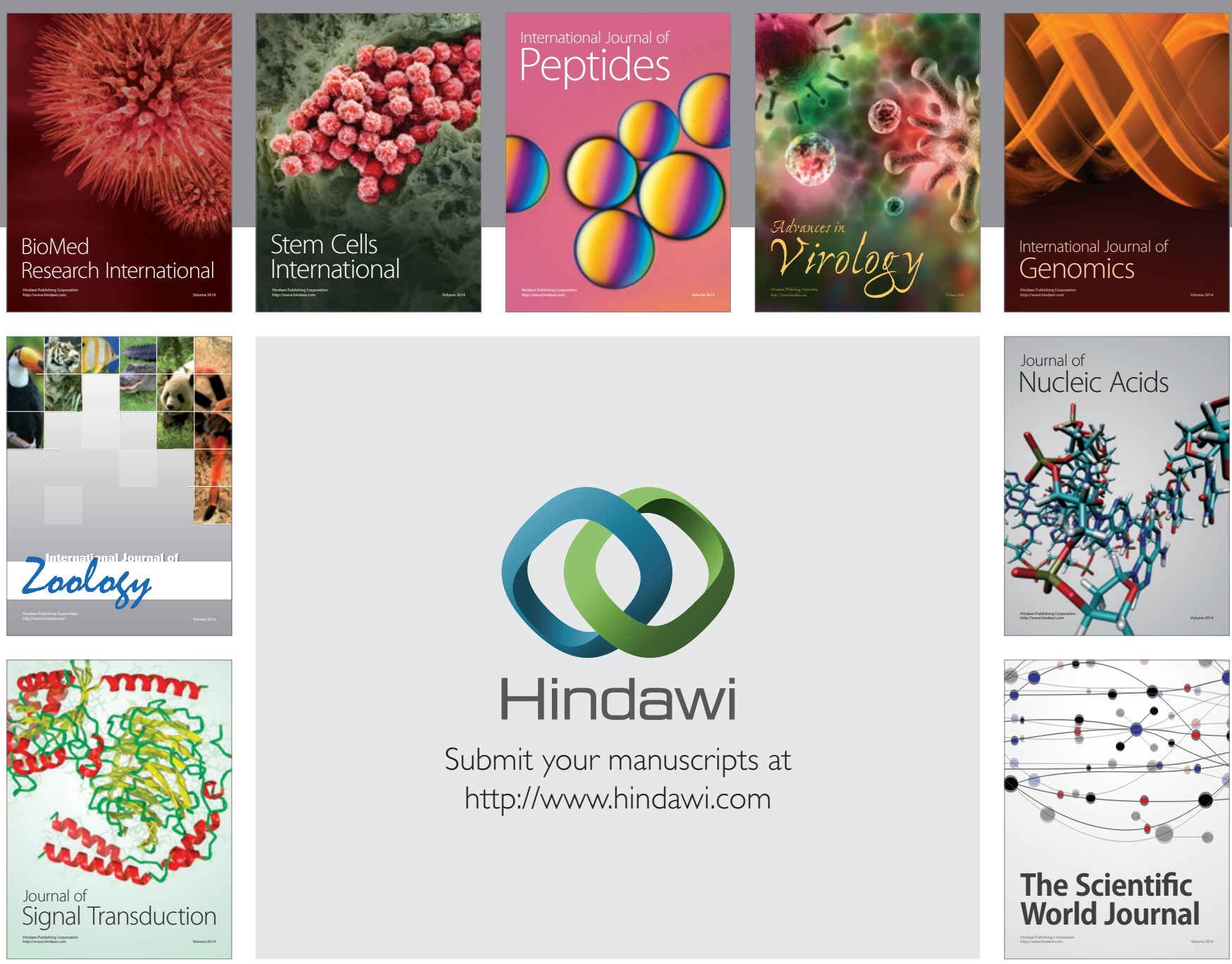

Submit your manuscripts at

http://www.hindawi.com
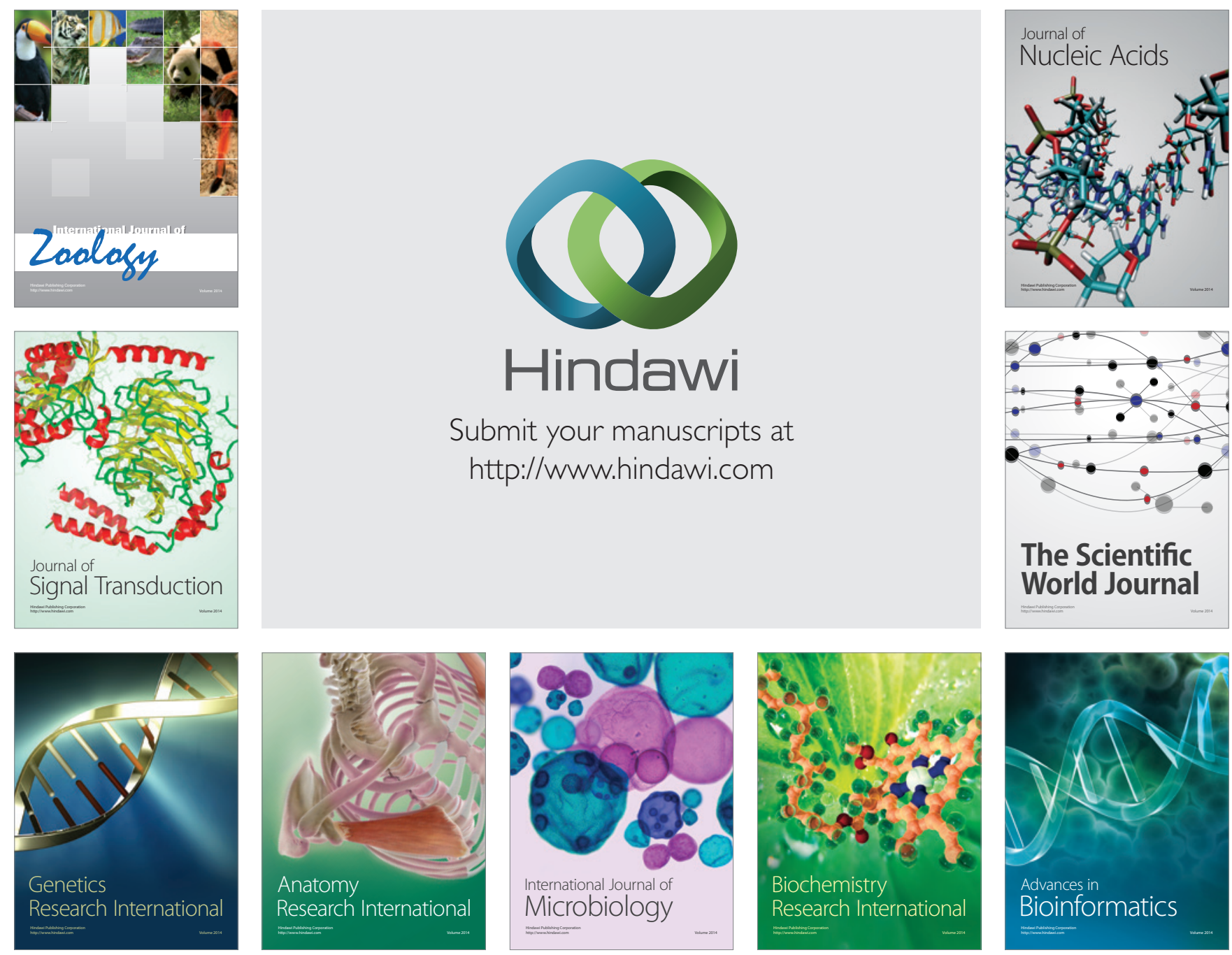

The Scientific World Journal
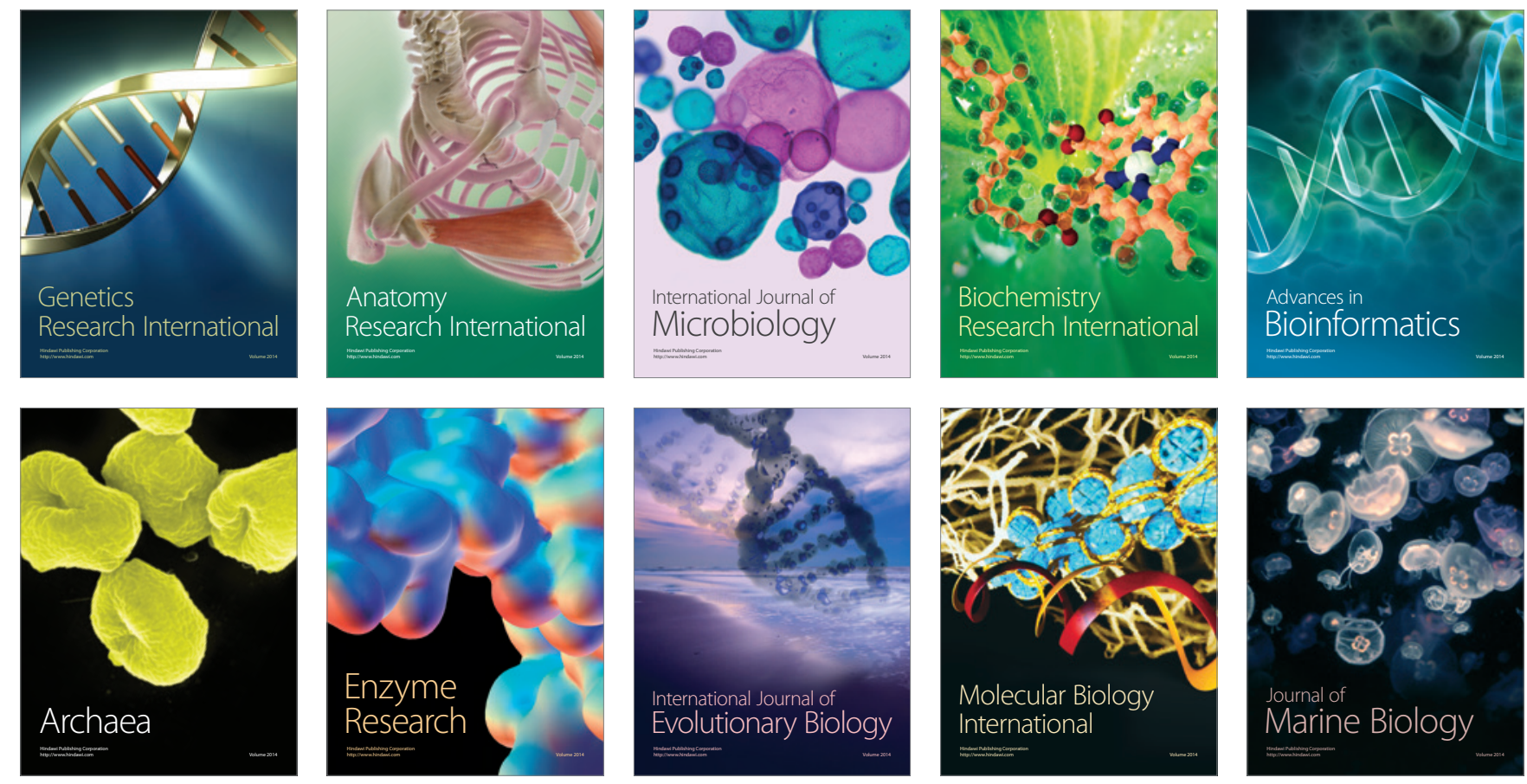